Universidad de Lima

Facultad de Derecho

Carrera de Derecho

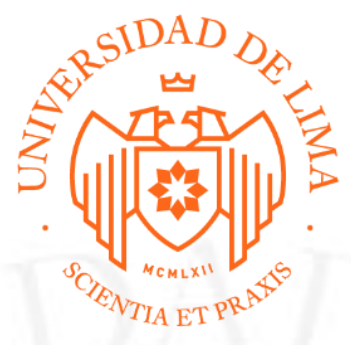

\title{
EXPEDIENTES CIVIL: "INDEMNIZACIÓN POR DAÑOS Y PERJUICIOS" Y CONSTITUCIONAL: "PROCESO DE AMPARO"
}

Trabajo de suficiencia profesional para optar el Título Profesional de Abogada

Carmen Daniela Alvítez Ramírez

Código 20100047

Lima - Perú

abril de 2019 


\section{EXPEDIENTES CIVIL: "INDEMNIZACIÓN POR DAÑOS Y PERJUICIOS"}

Materia: Indemnización por daños y perjuicios

No de Expediente: 28357-2006-0-1801-JR-CI-16

\section{RESUMEN}

Se trata de un proceso en el que el demandante interpone una demanda de indemnización por daños y perjuicios debido a un accidente laboral contra una empresa, a fin de que cumpla con pagarle la suma de S/. 150,000.00 nuevos soles, más intereses desde el momento del accidente y costas, costos del proceso.

\section{CONSTITUCIONAL: "PROCESO DE AMPARO"}

Materia: Proceso de Amparo

$\mathrm{N}^{\mathrm{o}}$ de Expediente: 62577-2005-0-1801-JR-CI-10

\section{RESUMEN}

Se trata de una demanda de amparo contra Essalud y un informe médico de alta otorgado a favor de la hija de la recurrente, con diagnóstico de Esquizofrenia Paranoide. El objeto del proceso es suspender el informe médico y, en consecuencia, se deje sin efecto la orden de alta para la hija, debido al diagnóstico que presenta, argumentando que dicho documento vulnera su derecho constitucional a la salud. De igual manera, solicita que su hija tenga derecho a la salud de manera permanente e indefinida en dicho hospital. 